\title{
Dorsal roof potentials: effects of acoustic and visual stimuli
}

Some supraspinal structures exert a powerful but selective modulation upon spinal reflexes and sensory transmission. In most cases the effect was, however, elicited by electrical stimulation of supraspinal sites $^{4-6}$.

In spite of the fact that photic or auditory stimulation is capable of eliciting reflex pyramidal discharge ${ }^{1,3}$ or ventral root discharge after pyramidectomy ${ }^{3}$, the effect of this sensory activation upon dorsal root potentials (DRPs) has, with one exception ${ }^{7}$, been ignored. Mallart ${ }^{7}$ produced DRPs with auditory and visual stimulation. The present study was designed to compare the influence of descending impulses evoked by photic or auditory input upon DRPs and spinal reflexes.

Acute experiments were performed on cats under chloralose anesthesia (50-60 $\mathrm{mg} / \mathrm{kg}$, i.p.). After tracheostomy and femoral vein cannulation, a spinal laminectomy was performed to expose the spinal cord from $\mathrm{L}_{6}$ to $\mathrm{S}_{1}$. A surrounding skin pouch was filled with mineral oil that was kept at $38^{\circ} \mathrm{C}$. The animal was then immobilized with gallamine triethiodide (Flaxedil) and artificially ventilated to maintain expired gas $\mathrm{CO}_{2}$ concentration between 3-4\%. For a 'pyramidal' preparation the progress of an acute surgical transection of the medulla at the obex was evaluated by evoking lemniscal responses at the cortical somatosensory area I by stimulating an isolated dorsal root. When the evoked lemniscal responses became attenuated, transection was made further only laterally, sparing the middle region of about $5.0 \mathrm{~mm}$ in width. The adequacy of the section in the 'pyramidal' preparation was verified at conclusion of the experiment.

A brief flash or click at intensities that produced no or a negligible ventral root discharge was the non-somatic sensory stimulation. The DRP was obtained from an $L_{7}$ or $S_{1}$ dorsal rootlet by applying a brief, single electrical stimulus of $0.3-0.6 \mathrm{~mA}$ to the immediately adjacent dorsal rootlet. The ventral root reflex discharges were obtained by recording from a corresponding small ventral rootlet.

Excitability changes of spinal reflexes and DRPs were measured using photic or auditory stimulation as the conditioning stimulus and dorsal root stimulation as the testing stimulus. Both mono- and polysynaptic reflexes were facilitated for about 30-80 msec following photic stimulation (Fig. 1) and auditory stimulation (not illustrated). The changes occurred bilaterally. Facilitation of reflexes was often followed by a depression which reached a maximum at about $300 \mathrm{msec}$.

The effect upon DRPs is shown in Fig. 2. No DRPs could be elicited with the conditioning stimuli alone. The amplitudes of control DRPs were maximally decreased at a conditioning-testing (C-T) interval of about $50 \mathrm{msec}$ (Fig. 2B, C). Comparing Fig. 1 and Fig. 2 it is noted that DRP depression occurred during the period of facilitation of spinal reflexes. In one experiment the decrease in negative DRPs fluctuated around zero potential and an occasional positive potential was observed. No comparable changes in DRPs were observed in any 'pyramidal' preparation.

The results indicate that the descending impulses elicited by photic or auditory input are capable of facilitating somatosensory inflow by affecting the membrane potential at the terminals of spinal primary afferents, as indicated by changes in 


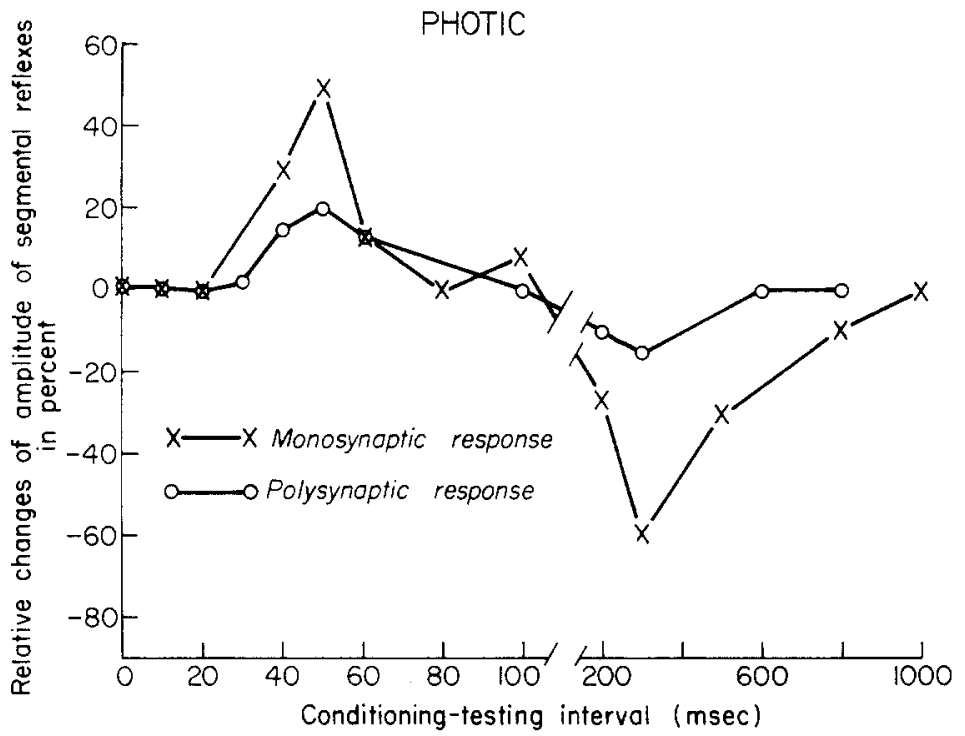

Fig. 1. Effect of photic stimulation upon spinal mono- and polysynaptic reflexes. Recordings were taken from an $\mathrm{L}_{6}$ ventral rootlet and test stimulation was applied to the $\mathrm{L}_{6}$ dorsal root. Photic stimulation was given as the conditioning stimulus. Each point is an average of 20 responses. Note the early facilitation and late depression.



C.

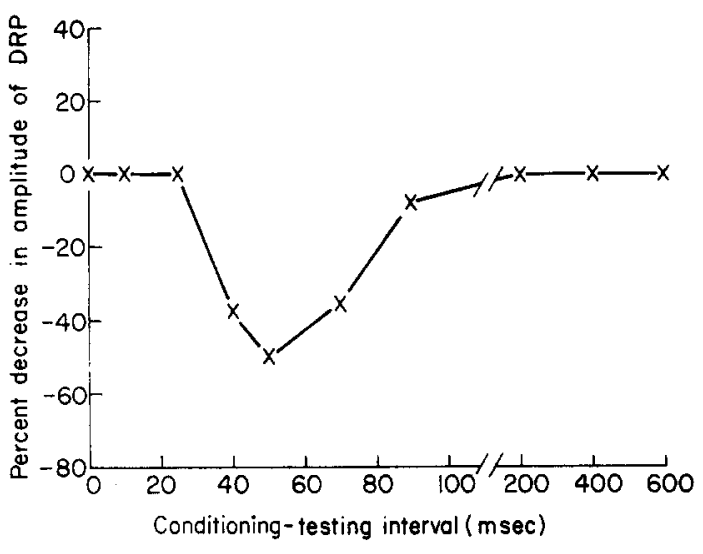

Fig. 2. Effect of photic or auditory stimulation upon the DRP. Recordings were taken from an $\mathrm{L}_{6}$ dorsal rootlet and test stimulation was applied to an immediately adjacent dorsal rootlet. Sensory stimulation was the conditioning stimulus. Numbers in each trace are $\mathrm{C}-\mathrm{T}$ intervals in msec and small letter $\mathrm{C}$ indicates control, i.e. the DRP test response alone. Each trace is the average response of 20 recordings. A, auditory stimulation. B, photic stimulation. $\mathrm{C}$, time course for the decrease in negative DRP plotted from $B$. Negativity upward.

Brain Research, 18 (1970) 189-191 
DRPs ${ }^{9}$. The observed changes in DRPs are probably exerted via an extrapyramidal route because they were absent in the 'pyramidal' preparation and the predominant effect of pyramidal tract stimulation is to elicit negative DRPs ${ }^{4}$. Furthermore, it has been shown that a positive DRP can be evoked from lower brain stem stimulation ${ }^{6}$.

The effect of chloralose anesthesia upon the spinal cord reflexes has been studied in intact and spinal cats. In spinal preparations only a mild effect upon ventral root reflexes and DRPs was noted ${ }^{8}$. In intact preparations, a 'chloralose jerk' could be evoked, depending upon the dosage and the way the stimuli were presented ${ }^{2}$. In the present study, care was taken to prevent 'chloralose jerks', but the chloralose effect should be kept in mind in interpreting the data.

This work was supported by NIH Grant NB-04119 to Dr. L. T. Rutledge whose advice on this manuscript is appreciated.

Department of Physiology, Medical Science Building,

NAI-SHIN CHU The University of Michigan Medical School, Ann Arbor, Mich. 48104 (U.S.A.)

1 Adrian, E. D., AND Moruzzi, G., Impulses in the pyramidal tract, J. Physiol. (Lond.), 97 (1939) 153-199.

2 Alvord, E. C., AND Fuortes, M. G. F., A comparison of generalized reflex myoclonic reactions elicitable in cats under chloralose anesthesia and under strychnine, Amer. J. Physiol., 176 (1954) 253-261.

3 Buser, P., Ascher, P., Bruner, J., Jassik-Gerschenfeld, D., And Sindberg, R., Aspects of sensorimotor reverberation to acoustic and visual stimuli. The role of primary specific cortical areas. In G. Moruzzi, A. Fessard AND H. H. JASPER (Eds.), Brain Mechanisms, Progress in Brain Research, Vol. 1, Elsevier, Amsterdam, 1963, pp. 294-322.

4 Fetz, E. E., Pyramidal tract effects on interneurons in the cat lumbar dorsal horn, J. Neurophysiol., 31 (1968) 69-80.

5 LUNDBERG, A., Supraspinal control of transmission in reflex paths to motoneurones and primary afferents. In J. C. ECCLES AND J. P. SCHADÉ (Eds.), Physiology of Spinal Neurons, Progress in Brain Research, Vol. 12, Elsevier, Amsterdam, 1964, pp. 197-219.

6 LUNDBERG, A., AND VYKLICKÝ, L., Brain stem control of reflex paths to primary afferents, Acta physiol. scand., 59, Suppl. 213 (1963) 91.

7 Mallart, A., Heterosegmental and heterosensory presynaptic inhibition, Nature (Lond.), 206 (1965) 719-720.

8 Shimamura, M., Yamauchi, T., ANd AOKI, M., Effects of chloralose anesthesia on spinal reflexes, Jap. J. Physiol., 18 (1968) 788-797.

9 WALL, P. D., Excitability changes in afferent fiber terminations and their relation to slow potentials, J. Physiol. (Lond.), 142 (1958) 1-21.

(Accepted December 4th, 1969) 